\title{
Dental Treatment for Dizziness and Joint Mobility Disorder Caused by Harmful Electromagnetic Waves
}

\author{
Yoshiro Fujii \\ Shin Kobe Dental Clinic, Kobe City, Japan \\ Email: shin-kobe-dentalclinic@s9.dion.ne.jp \\ Received 25 January 2015; accepted 6 February 2015; published 12 February 2015 \\ Copyright (C) 2015 by author and Scientific Research Publishing Inc. \\ This work is licensed under the Creative Commons Attribution International License (CC BY). \\ http://creativecommons.org/licenses/by/4.0/

(c) (i) Open Access

\section{Abstract}

With the development of an IT (Information Technology) society, the opportunity to use electronic devices, such as cell phones and personal computers, has increased. These electronic devices provide many benefits to society. However, there have been a number of reports of electromagnetic hypersensitivity (EHS) related to the use of electronic devices. The symptoms of EHS may include headaches, fatigue, tinnitus, dizziness, memory loss, irregular heartbeat, and skin trouble. Since the pathogenic mechanism of such conditions is not yet clear, further research is required. This report shows how a subject's dizziness and joint mobility disorder, caused by electromagnetic waves emitted by electronic devices, were cured by removing an onlay from the patient's mouth and replacing it with a gold alloy onlay. The result indicates that the subject's symptoms were caused by EHS. Although the symptoms were improved after the dental treatment, the underlying mechanism of the symptoms and the reason why this treatment is successful remain unclear. Further research is required to clarify these issues.

\section{Keywords}

Dental Treatment, Dizziness, Electromagnetic Hypersensitivity (EHS), Electromagnetic Waves, Joint Mobility Disorder

\section{Introduction}

With the development of an IT (Information Technology) society, the opportunity to use electronic devices, such as cell phones and personal computers, has become increasingly widespread and has enabled communication on a global scale [1] [2]. However, there have been many reports pertaining to health problems resulting from the 
electromagnetic waves emitted by such electronic devices [3]-[10]. Physically unpleasant symptoms including headache, fatigue, tinnitus, dizziness, memory loss, irregular heartbeat and whole-body skin lesions caused by exposure to electromagnetic waves are recognized as electromagnetic hypersensitivity (EHS) [11]-[15]. The author has reported that scoliosis can develop by exposure to electromagnetic waves [16]. The author also reported how a subject's involuntary movements caused by electromagnetic waves were treated using a gold alloy dental inlay [17]. This case report described how a subject's dizziness and joint mobility disorder caused by electromagnetic waves were treated using dental techniques. The treatment involved removing an old onlay, which was collecting harmful electromagnetic waves, and replacing it with a new gold alloy onlay. The new onlay was able to neutralize the harmful electromagnetic waves, which had been absorbed by the subject's old onlay. This treatment was very effective in eliminating the subject's dizziness and joint mobility disorder, which was caused by EHS.

\section{Case Report}

\section{Treatment and Results}

A 58-year-old woman was suffering from dizziness and joint mobility disorder. After examining the subject, the author proposed that the symptoms were the result of EHS. An experiment was designed to test this hypothesis. First, the subject was instructed to stand about one meter away from a personal computer (PC) screen. At this distance, the subject felt dizzy and exhibited a sense of balance dysregulation accompanied by an overall uncomfortable feeling (Figure 1). In a second test, the subject stood about three meters away from the PC screen. At this distance, she could touch the floor when bending forwards (Figure 2). In a third test, the subject was instructed to stand 1.5 meters away from the PC screen. At this distance, the subject was not able to extend her hands all the way to the floor. She could only reach a point approximately $30 \mathrm{~cm}$ from the floor (Figure 3 ). In a forth test, the lower half of the subject's face was covered with aluminum foil to shield her mouth from the harmful electromagnetic waves (Figure 4). Subsequently, the first three tests were repeated. The subject showed some improvement in her level of dizziness, sense of balance, and joint flexibility at all three distances $(1 \mathrm{~m}, 1.5$ $\mathrm{m}$, and $3 \mathrm{~m}$ ). The results of these tests indicated that some material in the subject's mouth was likely accumulating harmful electromagnetic waves. In brief, some foreign material was acting like an antenna.

Thus, the Bi-Digital O-ring Test [18] was used to identify this foreign material. First, an active cell phone was placed near the subject. Second, the author's assistant touched the suspicious dental material in the subject's mouth with a conductive probe, while making an O-ring with the thumb and another finger. Third, the author tested the strength of the assistant's O-ring by trying to split it apart by pulling on the assistant's fingers. If the assistant's grip strength was judged to be weaker than usual, then the material that the probe was touching was classified as a likely collector of harmful electromagnetic waves (Figure 5).

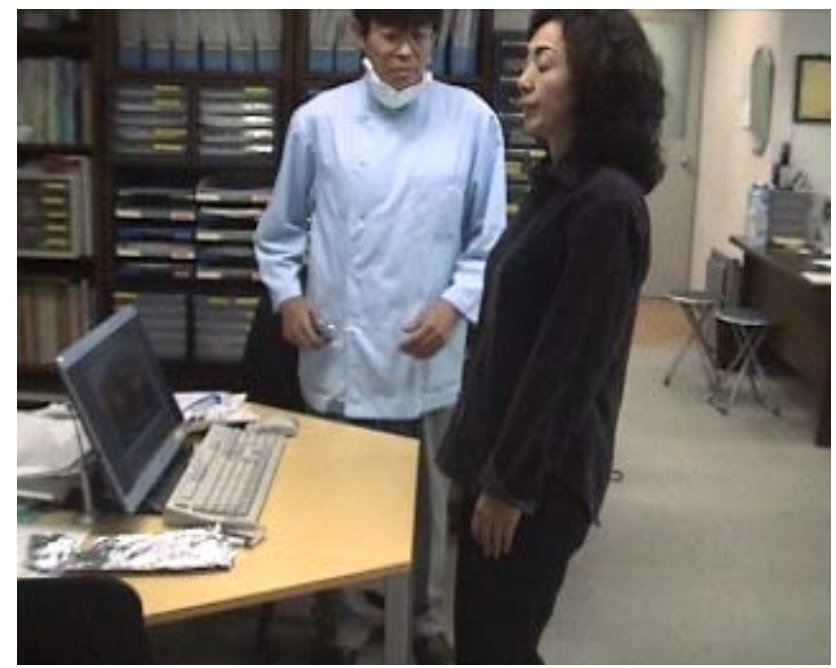

Figure 1. The subject is standing at a distance of about one meter from a PC screen. Notice the way the subject is leaning back and the expression of discomfort on her face. 


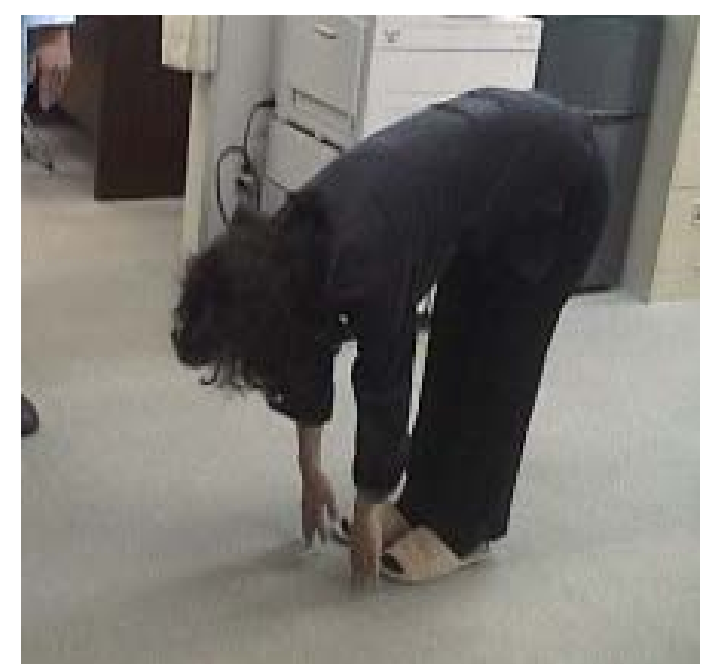

Figure 2. The subject is standing three meters away from the PC screen. Note how her fingers touch the floor.

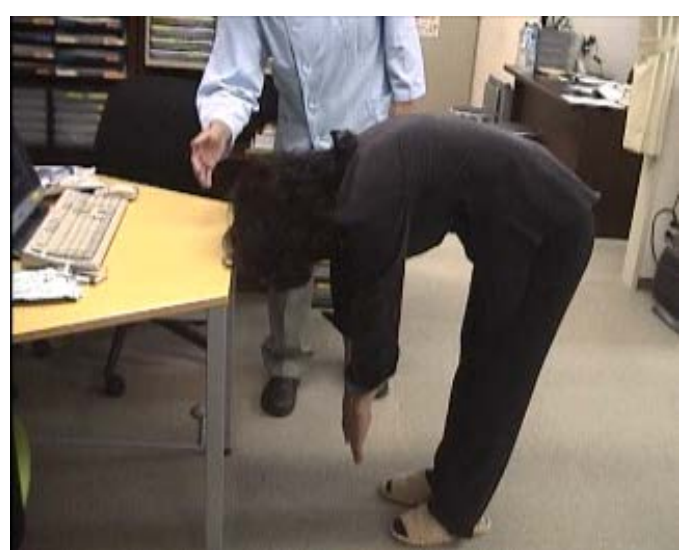

Figure 3. The subject is standing 1.5 meters away from the PC screen. Note the reduced flexibility compared with that in Figure 2. Her fingers are about $30 \mathrm{~cm}$ above the floor.

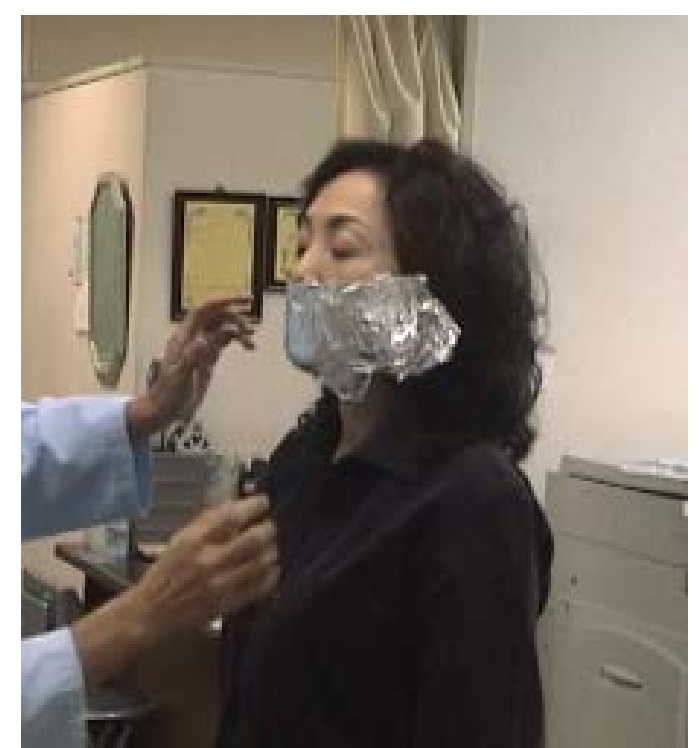

Figure 4. The lower half of the subject's face is covered with aluminum foil. 


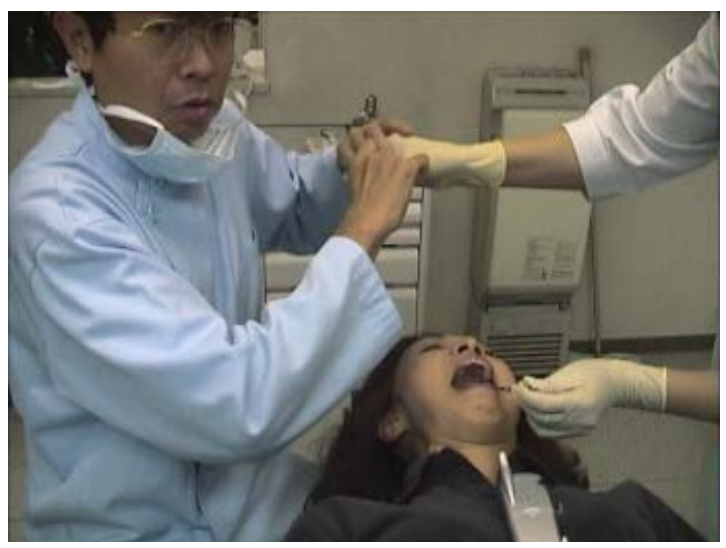

Figure 5. The author (in blue) can be seen testing the O-ring strength of his assistant (with latex gloves), while the assistant touches the suspected material in the subject's mouth with a conductive probe. Note the active cell phone resting on the subject's body.

During the Bi-Digital O-ring test, the author noted significant weakening in his assistant's grip strength when the conductive probe was touching an onlay on the upper left first molar of the subject. This seemed to indicate that the onlay was collecting harmful electromagnetic waves. Therefore, the onlay was removed (Figure 6). Next, the Bi-Digital O-ring test [18] was used to select a new onlay and adhesive cement. During this procedure, the subject held an active cell phone in her hand while various metal samples were placed on her palm, one at a time, with the author testing the subject's O-ring grip strength. A similar procedure was followed for the adhesive cement. Following these tests, a gold alloy onlay was selected (Au 86.0\%, Pt 11.8\%; others: Ir, Zn, In, Fe, Mn).

After the new onlay was set in the subject's mouth, she showed dramatic physical improvements when exposed to electromagnetic waves. The subject's joint mobility significantly improved. Even at a distance of only 1.5 meters from an active PC screen, she was able to touch the floor with her fingers (Figure 7). She also reported that she no longer felt dizzy when close to an electromagnetic source. The author followed up with the subject for the next six months. The subject did not report any reoccurrences of her previously reported symptoms.

\section{Discussion}

With regard to the relationship between brain tumors and electromagnetic waves emitted by cell phones, the Interphone Study Group had concluded that there was no increase in the risk of developing glioma or meningioma with the use of mobile phones. The authors also found that there were suggestions of an increased risk of glioma at the highest exposure levels; however, bias and error prevent a causal interpretation. Thus, the possible effects of long-term heavy use of mobile phones require further investigation [19]. Moreover, the WHO/International Agency for Research on Cancer (IARC) has classified radiofrequency electromagnetic fields as Group 2B (agents that are possibly carcinogenic to humans), based on an increased risk for glioma, a malignant type of brain cancer associated with wireless phone use, in 2011 [20]. Neither do other reports support an association between the use of cell phones and the development of brain nor salivary gland tumors, leukemia, nor other cancers [21][23]. However, these reports did not sufficiently evaluate the risks among long-term heavy cell phone users over long induction periods [21]. Accordingly, further studies are required to account for longer exposure periods, particularly with respect to slow-growing intracranial tumors [22].

The author has previously published several reports on the relationship between dentistry and electromagnetic waves [16] [17] [24]-[26]. Many articles only emphasize the convenience of these electronic devices without addressing the potentially negative influences of the emitted electromagnetic waves on the body [27]. Metals present within the body can act as antennas to collect harmful electromagnetic waves and induce the aforementioned symptoms. For example, scoliosis may be caused by dental implants that collect harmful electromagnetic radiation; however, pure gold may neutralize it [16]. In addition, electromagnetic waves emitted by cell phones can also cause balance disorders [26]. The underlying mechanism remains unknown, but decreased blood flow within the brain has been proposed [4]. The collection of symptoms caused by electromagnetic waves is known 


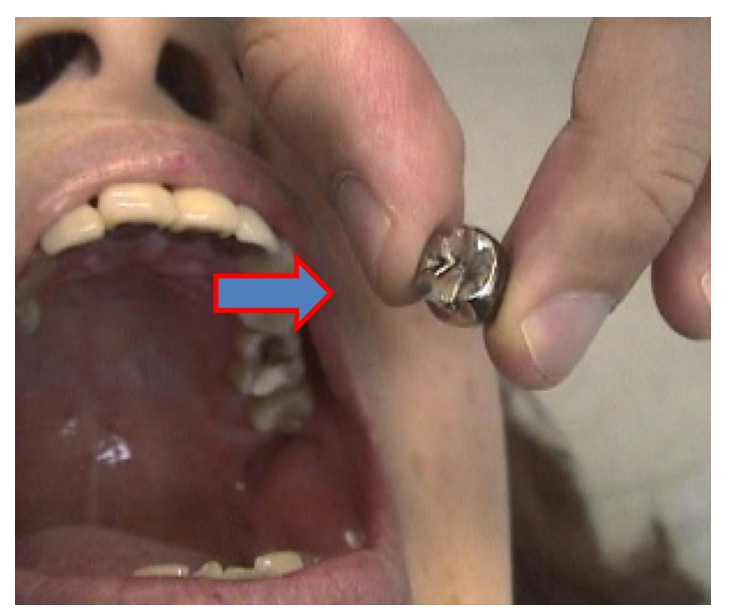

Figure 6. The arrow is pointing to the suspicious onlay, which was removed from the subject's upper left first molar.

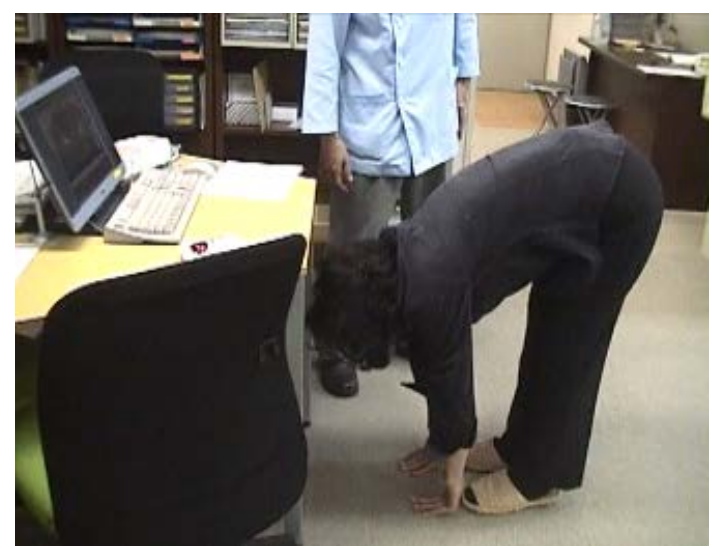

Figure 7. The subject is touching the floor with her fingers, while standing 1.5 meters away from the PC screen. Note the significant improvement in flexibility compared with that in Figure 3.

as electromagnetic wave hypersensitivity (EHS). In the aforementioned case, the subject's dizziness might have been due to decreased blood flow within the brain. However, the reason for the harmful electromagnetic waves causing joint mobility disorders is still unclear; therefore, further studies are required. Hence, the author sought to neutralize and reverse the effects of the electromagnetic waves. The old onlay, which might have been collecting harmful electromagnetic waves, was removed and replaced with a new gold alloy onlay on the subject's upper left first molar. Although the exact composition of the old onlay is unknown, it was probably a silver and palladium alloy. Despite the removal of the old onlay leading to some improvement in the subject's physical condition, it was not considered to be sufficient. However, the new gold alloy onlay setting was very effective in terms of further improving the subject's condition. Therefore, this case describes a two-part treatment. First, the material that collected harmful electromagnetic waves was removed to limit the amount of radiation being collected in the subject's mouth. Second, the onlay was replaced with a gold alloy onlay to neutralize the harmfulness of electromagnetic waves. To select the proper dental alloy for neutralizing the electromagnetic waves, the Bi-Digital O-ring Test was used [18]. On the basis of previous findings, gold may neutralize the harmful effects of the electromagnetic waves emitted by a cell phone [16] [17]. The Bi-Digital O-ring Test indicates the deleterious effects of electromagnetic waves on the body [28] [29] and may be a useful diagnostic tool for preventing the harmful effects of electromagnetic waves. Hence, the author used this test to select the proper dental alloy to improve the patient's condition. However, the underlying mechanism of this neutralization is not yet clear; therefore, further studies involving the cooperation of the medical and physical sciences are required.

The author's research has shown that the removal of metals that collect harmful electromagnetic waves from patients may be useful for preventing and treating EHS [26]. In addition, maintaining a sufficient distance from 
cell phones could decrease some of the harmful effects of electromagnetic waves and may permit short-duration, lower-risk use of cell phones. The effects of electromagnetic waves on the body are not yet clear. According to the report of Hagström et al., the most commonly perceived EHS-triggering sources are personal computers and mobile phones [30]. In addition, the best way to decrease EHS symptoms is to avoid electromagnetic fields [30]. The avoidance and neutralization of harmful electromagnetic radiation with dental fillings is not well known. Hence, the treatment method introduced in this paper could become an important approach for the treatment of EHS.

This experiment was performed in the region of Rayleigh (near field), because the radio wave length from the PC screen $(50-60 \mathrm{~Hz})$ is $6000 \mathrm{~km}-5000 \mathrm{~km}$. Therefore, the distance from PC screen to the border of near field is about $830 \mathrm{~km}$ to $1000 \mathrm{~km}$.

\section{Conclusion}

As the use of electronic devices continues to increase, EHS is sure to become a bigger issue. In addition to the symptoms commonly associated with EHS (headaches, fatigue, tinnitus, dizziness, memory loss, irregular heartbeat, skin trouble, involuntary body movement and balance dysregulation), current research indicates that joint mobility disorder can be caused by EHS. The best way to improve EHS symptoms seems to be avoidance of electromagnetic waves. As this case illustrates, one method for reducing exposure to electromagnetic waves involved is the removal and replacement of dental materials which attract and/or collect such waves. Furthermore, this case shows how the Bi-Digital O-ring Test can be a useful diagnostic tool for identifying materials which attract/or collect electromagnetic waves, and how the same test can also be used to select the proper dental alloy for neutralizing harmful electromagnetic waves. There are many aspects of these results for which the mechanism remains unclear. However, this approach has the potential to significantly improve the lives of some EHS patients.

\section{References}

[1] Geser, H. (2004) Towards a Sociological Theory of the Mobile Phone, Release 3.0. University of Zurich, Zurich. http://socio.ch/mobile/t geser1.htm/

[2] Van Dijk, J. and Hacker, K. (2003) The Digital Divide as a Complex and Dynamic Phenomenon, The Information Society, 19, 315-326. http://dx.doi.org/10.1080/01972240309487

[3] http://www.holistic-dentistry.net/blog/2013/07/entry 242/

[4] Aalto, S., Haarala, C., Brück, A., Sipilä, H., Hämäläinen, H. and Rinne, J.O. (2006) Mobile Phone Affects Cerebral Blood Flow in Humans. Journal of Cerebral Blood Flow \& Metabolism, 26, 885-900. http://dx.doi.org/10.1038/sj.jcbfm.9600279

[5] Feychting, M., Jonsson, F., Pedersen, N.L. and Ahlbom, A. (2003) Occupational Magnetic Field Exposure and Neurodegenerative Disease. Epidemiology, 14, 413-419. http://dx.doi.org/10.1097/01.EDE.0000071409.23291.7b

[6] Håkansson, N., Gustavsson, P., Johansen, C. and Floderus, B. (2003) Neurodegenerative Diseases in Welders and Other Workers Exposed to High Levels of Magnetic Fields. Epidemiology, 14, 420-426. http://dx.doi.org/10.1097/01.EDE.0000078446.76859.c9

[7] Ahlbom, A. (2001) Neurodegenerative Diseases, Suicide and Depressive Symptoms in Relation to EMF. Bioelectromagnetics, 22, S132-S143. http://dx.doi.org/10.1002/1521-186X(2001)22:5+<::AID-BEM1029>3.0.CO;2-V

[8] Linet, M.S., Hatch, E.E., Kleinerman, R.A., Robison, L.L., Kaune, W.T., Friedman, D.R., Severson, R.K., Haines, C.M., Hartsock, C.T., Niwa, S., Wacholder, S. and Tarone, R.E. (1997) Residential Exposure to Magnetic Fields and Acute Lymphoblastic Leukemia in Children. The New England Journal of Medicine, 337, 1-7. http://dx.doi.org/10.1056/NEJM199707033370101

[9] Röösli, M., Moser, M., Baldinini, Y., Meier, M. and Braun-Fahrländer, C. (2007) Symptoms of Ill Health Ascribed to Electromagnetic Field Exposure-A Questionnaire Survey. International Journal of Hygiene and Environmental Health, 207, 141-150. http://dx.doi.org/10.1078/1438-4639-00269

[10] Edelstyn, N. and Oldershaw, A. (2002) The Acute Effects of Exposure to the Electromagnetic Field Emitted by Mobile Phones on Human Attention. NeuroReport, 13, 119-121. http://dx.doi.org/10.1097/00001756-200201210-00028

[11] Rea, W., Pan, Y., Yenyves, E., Sujisawa, I., Suyama, H., Samadi, N. and Ross, G. (1991) Electromagnetic Field Sensitivity. Journal of Bioelectricity, 10, 241-256.

[12] Rubin, G.J., Das Munshi, J. and Wessely, S. (2005) Electromagnetic Hypersensitivity: A Systematic Review of Provo- 
cation Studies. Psychosomatic Medicine, 67, 224-232. http://dx.doi.org/10.1097/01.psy.0000155664.13300.64

[13] Rubin, G.J., Das Munshi, J. and Wessely, S. (2006) A Systematic Review of Treatments for Electromagnetic Hypersensitivity. Psychotherapy and Psychosomatics, 75, 12-18. http://dx.doi.org/10.1159/000089222

[14] Leitgeb, N. (2009) Electromagnetic Hypersensitivity. Advances in Electromagnetic Fields in Living Systems, 5, 167197. http://dx.doi.org/10.1007/978-0-387-92736-7_5

[15] Kimata, H. (2005) Microwave Radiation from Cellular Phones Increases Allergen-Specific IgE Production. Allergy, 60, 838-839. http://dx.doi.org/10.1111/j.1398-9995.2005.00802.x

[16] Fujii, Y. (2012) Do Dental Implants Cause Scoliosis? A Case Report. Personalized Medicine Universe, 1, 79-80. http://dx.doi.org/10.1016/j.pmu.2012.05.012

[17] Fujii, Y. (2014) Gold Alloy Dental Inlay for Preventing Involuntary Body Movements Caused by Electromagnetic Waves Emitted by a Cell Phone. Open Journal of Antennas and Propagation, 2, 37-43. http://dx.doi.org/10.4236/ojapr.2014.24005

[18] Omura, Y. (1990) Bi-Digital O-Ring Test for Imaging and Diagnosis of Internal Organs of a Patient. US Patent No. 5188107.

[19] Interphone Study Group (2010) Brain Tumor Risk in Relation to Mobile Telephone Use: Results of the Interphone International Case-Control Study. International Journal of Epidemiology, 39, 675-694. http://dx.doi.org/10.1093/ije/dyq079

[20] WHO (2011) IARC Classifies Radiofrequency Electromagnetic Fields as Possibly Carcinogenic to Humans. http://www.iarc.fr/en/media-center/pr/2011/pdfs/pr208_E.pdf

[21] Johansen, C., Boice Jr., J.D., McLaughlin, J.K. and Olsen, J.H. (2001) Cellular Telephones and Cancer-A Nationwide Cohort Study in Denmark. Journal of the National Cancer Institute, 93, 203-207. http://dx.doi.org/10.1093/jnci/93.3.203

[22] Inskip, P.D., Tarone, R.E., Hatch, E.E., Wilcosky, T.C., Shapiro, W.R., Selker, R.G., Fine, H.A., Black, P.M., Loeffler, J.S. and Linet, M.S. (2001) Cellular-Telephone Use and Brain Tumors. New England Journal of Medicine, 344, 79-86. http://dx.doi.org/10.1056/NEJM200101113440201

[23] Muscat, J.E., Malkin, M.G., Thompson, S., Shore, R.E., Stellman, S.D., McRee, D., Neugut, A.I. and Wynder, E.L. (2000) Handheld Cellular Telephone Use and Risk of Brain Cancer. JAMA, 284, 3001-3007. http://dx.doi.org/10.1001/jama.284.23.3001

[24] Fujii, Y. (2007) The Dental Treatment that Used Environment of Electromagnetic Wave. Acupuncture and ElectroTherapeutics Research, 32, 291.

[25] Fujii, Y. (2009) The Consideration of the Electromagnetic Wave in Dental Material Substitution. Acupuncture and Electro-Therapeutics Research, 34, 89.

[26] Fujii, Y. (2014) Sensation of Balance Dysregulation Caused/Aggravated by a Collection of Electromagnetic Waves in a Dental Implant. Open Journal of Antennas and Propagation, 2, 29-35. http://dx.doi.org/10.4236/ojapr.2014.23004

[27] http://www.healthit.gov/providers-professionals/benefits-electronic-health-records-ehrs

[28] Omura, Y. and Losco, M. (1993) Electro-Magnetic Fields in the Home Environment (Color TV, Computer Monitor, Microwave Oven, Cellar Phone, etc.) as Potential Contributing Factors for the Induction of Oncogen C-Fos Ab1, Oncogen C-Fos Ab2, Integrin Alpha 5 Beta 1 and Development of Cancer, as Well as Effects of Microwave on Amino Acid Composition of Food and Living Human Brain. Acupuncture and Electro-Therapeutics Research, 18, 33-73.

[29] Omura, Y., Losco, M., Omura, A.K., Yamamoto, S., Ishikawa, H., Takeshige, C., Shimotsuura, Y. and Muteki, T. (1991) Chronic or Intractable Medical Problems Associated with Prolonged Exposure to Unsuspected Harmful Environmental Electric, Magnetic, or Electro-Magnetic Fields Radiating in the Bedroom or Workplace and Their Exacerbation by Intake of Harmful Light and Heavy Metals from Common Sources. Acupuncture and Electro-Therapeutics Research, 16, 143-177.

[30] Hagström, M., Auranen, J. and Ekman, R. (2013) Electromagnetic Hypersensitive Finns: Symptoms, Perceived Sources and Treatments, a Questionnaire Study. Pathophysiology, 20, 117-122. http://dx.doi.org/10.1016/j.pathophys.2013.02.001 
Scientific Research Publishing (SCIRP) is one of the largest Open Access journal publishers. It is currently publishing more than 200 open access, online, peer-reviewed journals covering a wide range of academic disciplines. SCIRP serves the worldwide academic communities and contributes to the progress and application of science with its publication.

Other selected journals from SCIRP are listed as below. Submit your manuscript to us via either submit@scirp.org or Online Submission Portal.
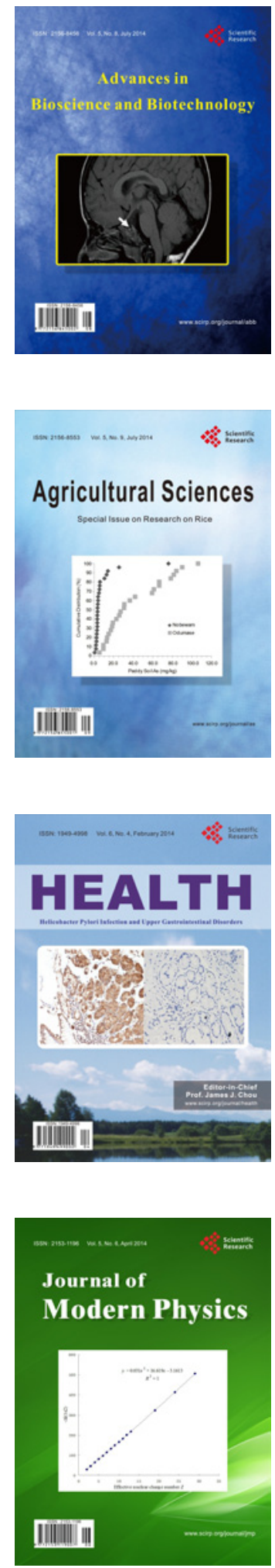
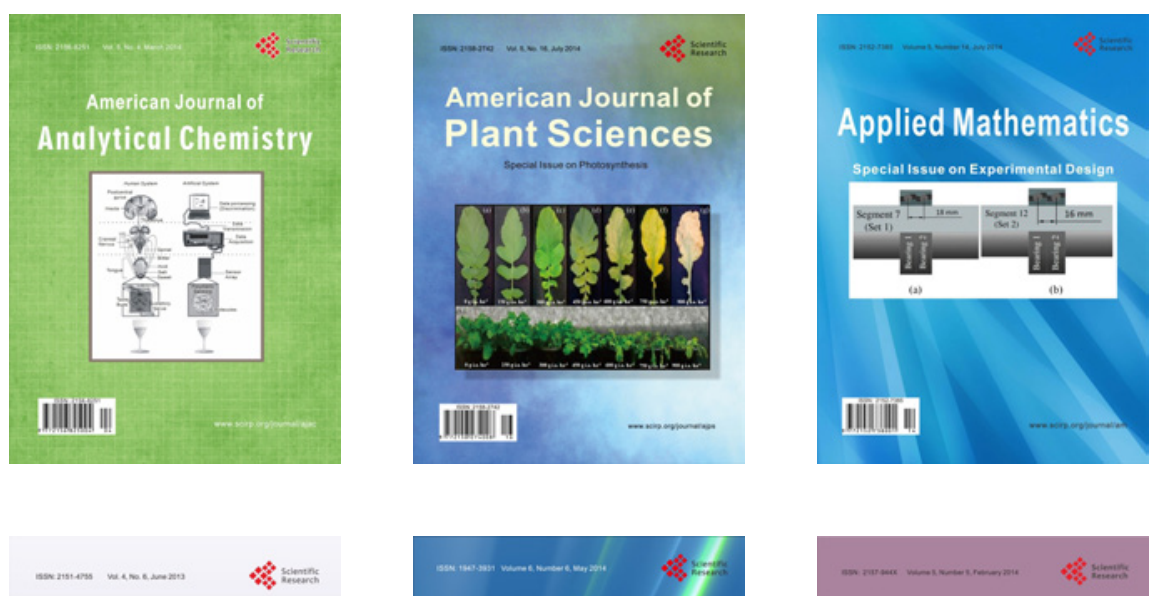

Creative Education
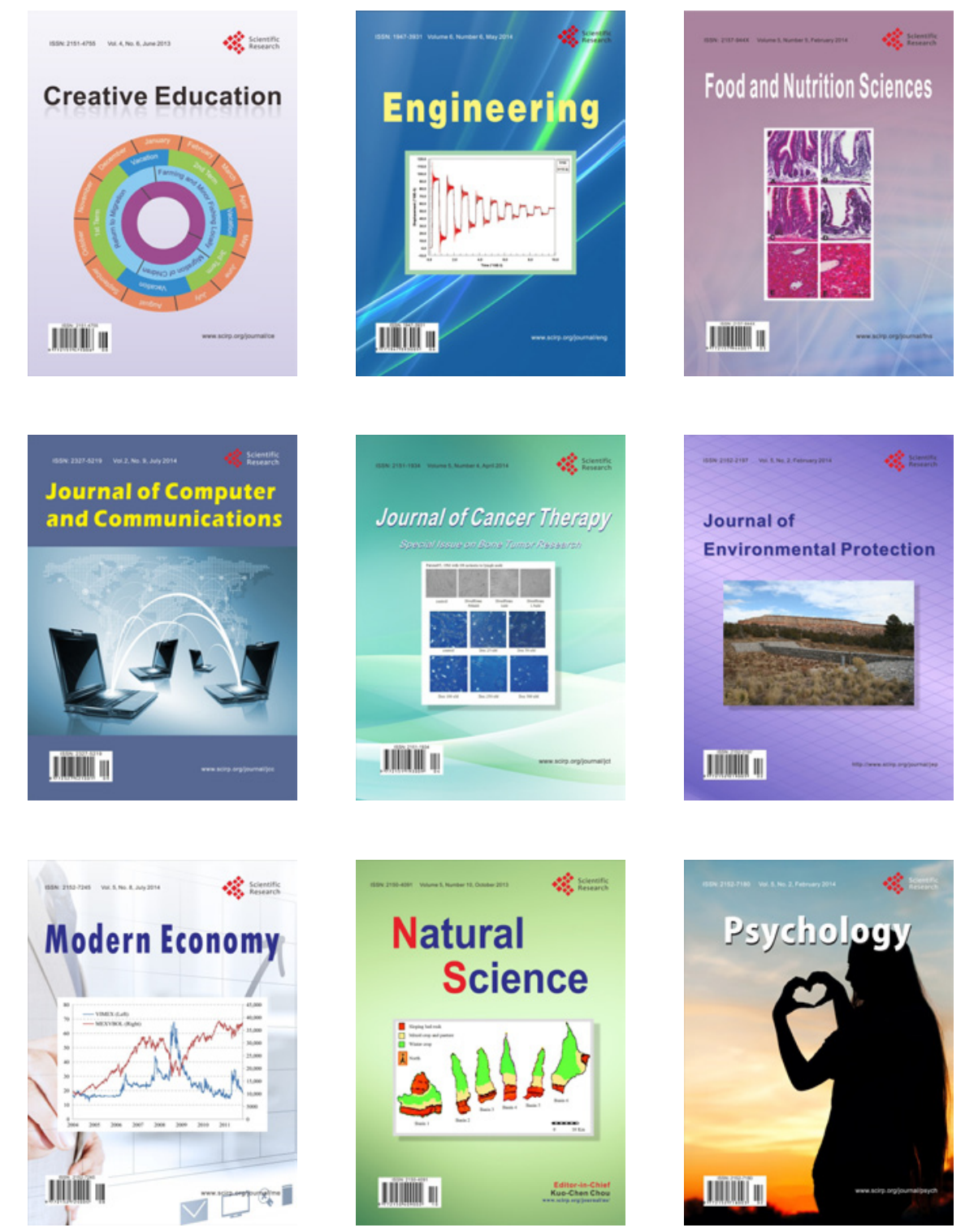